\title{
CARACTERIZACIÓN DE LAS CONDI- CIONES DE SEGURIDAD INDUSTRIAL EN LOS ASADEROS DE POLLO DEL BARRIO MEISSEN DE LA LOCALIDAD 19 DE CIUDAD BOLÍVAR
}

Liliana Vargas Puentes

Docente Corporación Universitaria Minuto de Dios UNIMINUTO. Programa de Administración en Salud Ocupacional.

Correo electrónico: Ivargar@uniminuto.edu.co

Yolanda López Reyes

Yesid Fernando Balaguera Jefrey Mahecha Garay

Juan Moreno Castro

Diana Díaz Aragón

Paola Santiago Cantor

Juan Parra Chilito

Alejandro Barrera Donoso

Albeiro Martínez Anaya

Edna López Martínez

Nicolás Cañón Alfonso

Estudiantes de octavo semestre en el programa académico de Administración en Salud Ocupacional.

\section{Resumen}

En los asaderos de pollo del barrio Meissen de la Localidad 19 de Ciudad Bolívar, se observa la exposición de trabajadores a diversos factores de riesgo, sin controles que minimicen la ocurrencia de un accidente o enfermedad laboral durante la ejecución de sus actividades; en consecuencia a esto, surge el interrogante: ¿cómo establecer estrategias de identificación de peligros, valoración y control de riesgos que conlleven a generar condiciones de seguridad requeridas para que los trabajadores de estos establecimientos no se vean afectados por la exposición a dichos factores en su actividad laboral? Como objetivo se plantea identificar los factores de riesgo asociados a la seguridad industrial en asaderos de pollos, ya que pueden generar graves consecuencias en los empleados. Siendo el enfoque metodológico mixto, ya que permitió la recolección y análisis de datos que aclararon los interrogantes identificados, además la exploración y reconocimiento de los riesgos presentes en el entorno laboral. Como instrumento de recolección informativa, se realizaron encuestas y unas visitas de campo a los colaboradores, quienes desconocen del tema de seguridad y salud en trabajo. En cuanto a la matriz, se evidencia una alta exposición a factores de riesgo biomecánicos (movimientos repetitivos) y riesgo público (por los entornos laborales). Concluyendo, los trabajadores desconocen el tipo de riesgos a los que están expuestos dentro de la realización de sus labores, los daños que generan a la salud y la afectación en su estabilidad social y familiar; además, se evidencia falta de estructuración del Sistema de Gestión de Seguridad y Salud en el Trabajo (SG-SST) dentro de cada establecimiento comercial, siendo una herramienta fundamental; por lo que no se han tenido en cuenta las medidas preventivas, haciéndose necesario generar planes de acción que mejoren las condiciones de bienestar de los trabajadores para que se mitigue la ocurrencia de enfermedades y accidentes laborales. 


\section{Planteamiento problema de investigación}

Esta investigación nace de la inexistencia de procesos de identificación, valoración y control de riesgos laborales presentes en las actividades desarrolladas por los trabajadores de los asaderos de pollos del barrio Meissen; la mayoría no cumple las normas de seguridad, evidenciando una inadecuada implementación de los protocolos de seguridad industrial.

Por consiguiente, surge la pregunta de investigación: ¿cómo establecer estrategias de identificación de peligros, valoración y control de riesgos que conlleven a generar condiciones de seguridad e higiene requeridas para que los trabajadores de los asaderos de pollo del barrio Meissen, no se vean afectados por la exposición a factores de riesgo presentes en sus actividades laborales?

\section{Introducción}

En los últimos años, la seguridad industrial ha logrado implementarse en los lugares de trabajo, ya que es importante que tanto empleadores como empleados conozcan los lineamientos necesarios, para garantizar el bienestar de los trabajadores a través de la identificación de peligros para así mismo determinar controles y evitar algún tipo de accidente o enfermedad laboral. Con base en lo anterior el semillero de investigación decide realizar la investigación.

\section{Marco teórico}

Los trabajadores de los asaderos de pollo que desarrollan cualquier actividad laboral están expuestos constantemente a factores de riesgo, los cuales podrían llegar a ocasionarles una enfermedad o un accidente laboral.

La preocupación por la cual se realiza la investigación, se debe a que se observa la poca seguridad que ofrecen los restaurantes a sus trabajadores; por ende la importancia de aplicar lo que indica la guía técnica GTS USNA 009 del 2007; que habla sobre la seguridad industrial, teniendo como objetivo principal la aplicación de disposiciones para un adecuado ambiente de trabajo, garantizando por parte de los empleadores la seguridad de sus trabajadores dentro del sitio de trabajo o lugar en el que se va a realizar la labor. 


\begin{tabular}{|c|c|}
\hline \multicolumn{2}{|r|}{ CLASES DE RIESGOS } \\
\hline RIESGO & DESCRIPCIÓN \\
\hline $\begin{array}{l}\text { RIESGO } \\
\text { BIOLÓGICO }\end{array}$ & $\begin{array}{l}\text { En este caso encontramos un grupo de agentes orgánicos, animados o } \\
\text { inanimados como los hongos, virus, bacterias, parásitos, pelos, plumas, } \\
\text { polen (entre otros), presentes en determinados ambientes laborales, } \\
\text { que pueden desencadenar enfermedades infectocontagiosas, } \\
\text { reacciones alérgicas o intoxicaciones al ingresar al organismo. }\end{array}$ \\
\hline $\begin{array}{l}\text { RIESGO } \\
\text { PSICOSOCIAL }\end{array}$ & $\begin{array}{l}\text { La interacción en el ambiente de trabajo, las condiciones de } \\
\text { organización laboral y las necesidades, hábitos, capacidades y demás } \\
\text { aspectos personales del trabajador y su entorno social, en un momento } \\
\text { dado pueden generar cargas que afectan la salud, el rendimiento en el } \\
\text { trabajo y la producción laboral. }\end{array}$ \\
\hline $\begin{array}{l}\text { RIESGOS } \\
\text { BIOMECÁNICOS }\end{array}$ & $\begin{array}{l}\text { Involucra todos aquellos agentes o situaciones que tienen que ver con } \\
\text { la adecuación del trabajo, o los elementos de trabajo a la fisonomía } \\
\text { humana. } \\
\text { Representan factor de riesgo los objetos, puestos de trabajo, máquinas, } \\
\text { equipos y herramientas cuyo peso, tamaño, forma y diseño pueden } \\
\text { provocar sobre-esfuerzo, asi como posturas y movimientos } \\
\text { inadecuados que traen como consecuencia fatiga física y lesiones } \\
\text { osteomusculares. }\end{array}$ \\
\hline RIESGO QUÍMICO & $\begin{array}{l}\text { Son todos aquellos elementos y sustancias que, al entrar en contacto } \\
\text { con el organismo, bien sea por inhalación, absorción o ingestión, } \\
\text { pueden provocar intoxicación, quemaduras o lesiones sistémicas, según } \\
\text { el nivel de concentración y el tiempo de exposición. }\end{array}$ \\
\hline RIESGO FÍsICO & $\begin{array}{l}\text { Se refiere a todos aquellos factores ambientales que dependen de las } \\
\text { propiedades físicas de los cuerpos, tales como carga física, ruido, } \\
\text { iluminación, radiación ionizante, radiación no ionizante, temperatura } \\
\text { elevada y vibración, que actúan sobre los tejidos y órganos del cuerpo } \\
\text { del trabajador y que pueden producir efectos nocivos, de acuerdo con la } \\
\text { intensidad y tiempo de exposición de los mismos. }\end{array}$ \\
\hline $\begin{array}{l}\text { CONDICIONES DE } \\
\text { SEGURIDAD } \\
\text { (RIESGO } \\
\text { ELÉCTRICO) }\end{array}$ & $\begin{array}{l}\text { Se refiere a los sistemas eléctricos de las máquinas, equipos, } \\
\text { herramientas e instalaciones locativas en general, que conducen o } \\
\text { generan energía y que, al entrar en contacto con las personas, pueden } \\
\text { provocar, entre otras lesiones, quemaduras, choque, fibrilación } \\
\text { ventricular, según sea la intensidad de la corriente y el tiempo de } \\
\text { contacto }\end{array}$ \\
\hline $\begin{array}{l}\text { CONDICIONES DE } \\
\text { SEGURIDAD } \\
\text { (RIESGO } \\
\text { MECÁNICO) }\end{array}$ & $\begin{array}{l}\text { Contempla todos los factores presentes en objetos, máquinas, equipos, } \\
\text { herramientas, que pueden ocasionar accidentes laborales, por falta de } \\
\text { mantenimiento preventivo y/o correctivo, carencia de guardas de } \\
\text { seguridad en el sistema de transmisión de fuerza, punto de operación y } \\
\text { partes móviles y salientes, falta de herramientas de trabajo y elementos } \\
\text { de protección personal. (Universidad del valle. 2005). }\end{array}$ \\
\hline
\end{tabular}

Fuente: (S.A). (S.F). Actividad Laboral Segura. Recuperado de: https://leidymurillo. wordpress.com/seguridad-industrial/

\section{Objetivo general}

Establecer estrategias de identificación de peligros, valoración y control de riesgos para los trabajadores de asaderos de pollos, ubicados en el barrio Meissen localidad de Ciudad Bolívar.

\section{Objetivos específicos}

- Reconocer los factores de riesgo presentes en el entorno laboral que puedan desencadenar accidentes o enfermedades laborales que afecten la calidad de vida no solo del trabajador sino la de su familia.

- Establecer la percepción del riesgo que posee el trabajador frente a las actividades propias de su labor.

- Proponer medidas de intervención que permitan el control y la mitigación de todos los riesgos laborales presentes en el área de trabajo. 


\section{Metodología}

Se utilizó la metodología cualitativa, que permitió a través de la recolección y análisis de datos, aclarar interrogantes de la investigación, como lo expresan Hernández, Fernández y Baptista (2003). "El enfoque cualitativo utiliza la recolección y análisis de los datos para afinar las preguntas de investigación e interpretar los resultados" (p. 7), la investigación posee un carácter exploratorio y descriptivo, ya que se está indagando en un tema que no ha sido estudiado anteriormente y el objetivo consiste en examinar un tema poco estudiado o novedoso.

\section{Desarrollo de la investigación}

En la matriz de peligros se identificaron factores de riesgo, tales como biológicos, físicos, químicos, psicosociales y biomecánicos; también condiciones de seguridad como locativos, públicos, mecánicos y eléctricos, los cuales no cuentan con medidas de prevención que permitan mitigar o disminuir accidentes o enfermedades de origen laboral. Por otra parte, con las encuestas se evidenció que la mayoría de trabajadores desconocen temas relacionados con la seguridad y la salud en el trabajo y que la necesidad los obliga a laborar expuestos.

\section{Principales hallazgos}

Se logró identificar los factores de riesgos como los biomecánicos, condiciones de seguridad (locativos), biológicos, físicos, químicos, mecánicos y público; con una exposición al riesgo alta y los instrumentos de aplicación encuestas y entrevistas se verificó que los trabajadores desconocen las normas y temas de seguridad y salud en el trabajo, pero perciben las condiciones de riesgo a los cuales están expuestos.

Por lo anterior, se realiza un acercamiento con los administradores, donde se les brinda información de la importancia de implementar y de invertir en la seguridad industrial, se propusieron medidas de intervención que permitan el control y la mitigación de todos los riesgos laborales presentes en el lugar de trabajo.

\section{Bibliografía}

INCONTEC. (2017). Guía técnica GTS-USNA SECTORIAL009.Recuperadode:http://www.mincit.gov.co/loader.php?lServicio=Documentos\&IFuncion=verPdf\&id=23882\&name=GASTONOMIA-USNA009.pdf\&prefijo=file Asociación Chilena de seguridad (ACHS). (SF). Prevención de riesgos en bares, restaurantes y cafeterías. Recuperado de: http://www.achs.cl/portal/trabajadores/Capacitacion/CentrodeFichas/Paginas/Prevencion_de_riesgos_ en_bares_restaurantes_y_cafeterias.aspx

Correa, S. (2013). Investigación Cualitativa. Tipo fenomenológica. [Entrada de blog].Recuperado de:http://hilanasuskys.blogspot.com.co/2013/06/investigacion-cualitativa-tipo.html Hernández, R., Fernández, C \& Baptista, P. (2003) Metodología de la investigación. $3^{a}$ ed. México: Mc Graw Hill S.A. (2016). Identificación de peligros, evaluación y valoración de riesgos. Recuperado de: https://www.isotools. org/2016/09/27/identificacion-peligros-evaluacion-valoracion-los-riesgos-sg-sst/

(S.A). (S.F). Actividad laboral segura. Recuperado de: https://leidymurillo.wordpress.com/seguridad-industrial 